\title{
3D MODELING AND ANALYSIS OF TREE HARVESTING EQUIPMENT
}

\author{
Assoc. Dr. Eng. Dorin EFTIMIE \\ MECMET - The Research Center of Machines, \\ Mechanic and Technological Equipment \\ Engineering and Agronomy Faculty of Braila \\ "Dunarea de Jos" University of Galati
}

\begin{abstract}
The paper presents the $3 D$ modeling of a multifunctional equipment that can be attached to the excavator arm in order to prepare the wood material, being necessary for harvesting trees with high productivity.

The equipment performs operations of clamping the trunks of the trees with hydraulically driven claws, cutting operations with a chainsaw and the operation of moving the trunk of the tree with the help of rollers in both directions for cleaning branches and bark.

The CAE analysis of the requested parts confirms the correct design of this type of equipment.
\end{abstract}

KEYWORDS: tree harvesting equipment, 3D modeling, CAE analysis.

\section{OVERVIEW}

The operation of harvesting the trees by felling involves the successive passage of some phases, the observance of this order ensuring the fulfillment of the technological, forestry and labor protection conditions. These phases are:

- moving to the tree to be felled,

- choosing the direction of descent,

- preparation of the job,

- the impulse and orientation of the fall,

- smoothing and peeling the nail,

- cutting the ridge of the trunk.

Constructive solutions of equipment with high productivity have appeared in the field of tree harvesting.

Some models are developed and modified from simple cutting equipment to equipment capable of cutting more than one tree in a single grip. Other models are modified with the possibility of catching a single tree trunk, capable of cutting, removing branches and cutting them to a desired length

Adopting a new constructive solution for a tree harvesting equipment that can be attached to an excavator, at a higher productivity compared to the ones on the profile market, is necessary in developing this type of equipment.

\section{MULTIFUNCTIONAL EQUIPMENT FOR TREE HARVESTING}

This type of equipment is used in various fields of activity:

- forestry,

- land clearing of the forests for the revaluation of the wood,

- creation of the areas necessary for the construction of forest roads, roads, highways, etc.

- carrying out routes for electrical networks,

- creation of areas for the construction of industrial or tourist objectives.

The 3D model of the multifunctional tree harvesting equipment was designed using NX 8.0 software. [1] This type of equipment is suitable for any type of excavator on special tracks or tires. The hydraulic power required is within the usual limits of a middle-class excavator of 20 to 40 tons.

The multifunctional tree harvesting equipment (fig. 1) has the possibility to catch a single tree trunk, is capable of chain cutting (chainsaw), removing branches and cutting them to a desired length with the help of a chain (chainsaw). 


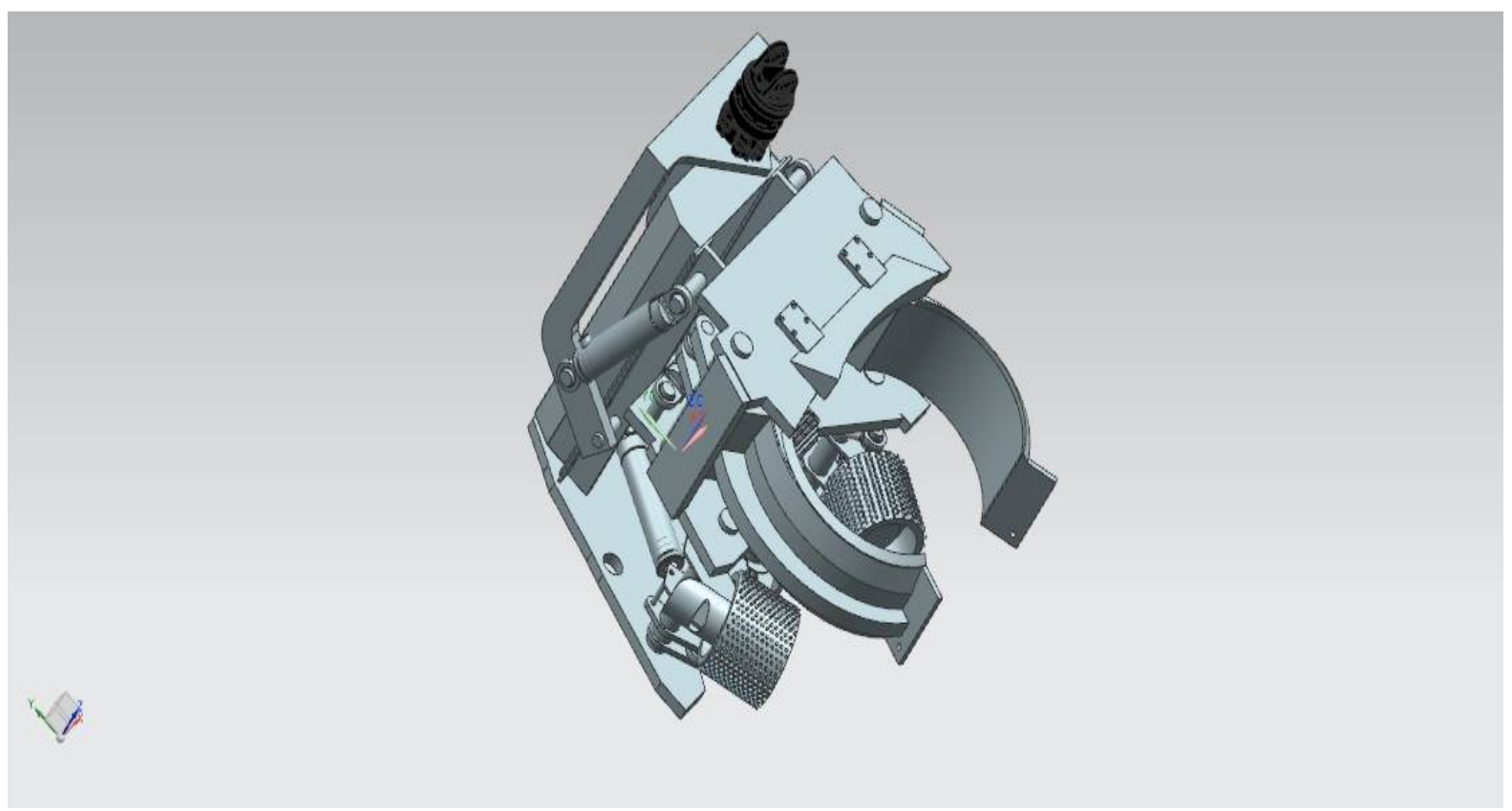

Fig. 1 - 3D model of multifunctional equipment for tree harvesting attached to the excavator arm

The multifunctional equipment for wood harvesting consists of 3 subsystems:

$\checkmark$ the subsystem for clamping the trunks with hydraulically driven claws;

$\checkmark$ the subsystem of the rollers to advance in both directions;

$\checkmark$ the subsystem for cutting with chain (chainsaw).

The claws of the equipment were designed for easy loading and unloading, it is equipped with a high speed chain cutting system (chainsaw) that ensures the cutting in any condition. The roller feed system allows the cutting of the branches and the cutting of the tree trunk with high productivity. The equipment has a simple design, is compact and easy to use in the operation of harvesting trees.

\subsection{THE CLAMPING SUBSYSTEM OF TRUNKS WITH HYDRAULICALLY DRIVEN CLAWS}

The subsystem for clamping the trunks (fig. 2) is composed of 2 jaws mirroring mounted on two axles fixed to the housing and 2 hydraulic cylinders that provide the opening and closing movements. The special knives that are used for cutting branches and cleaning the bark of the trees are fixed on the housing and on the jaws.

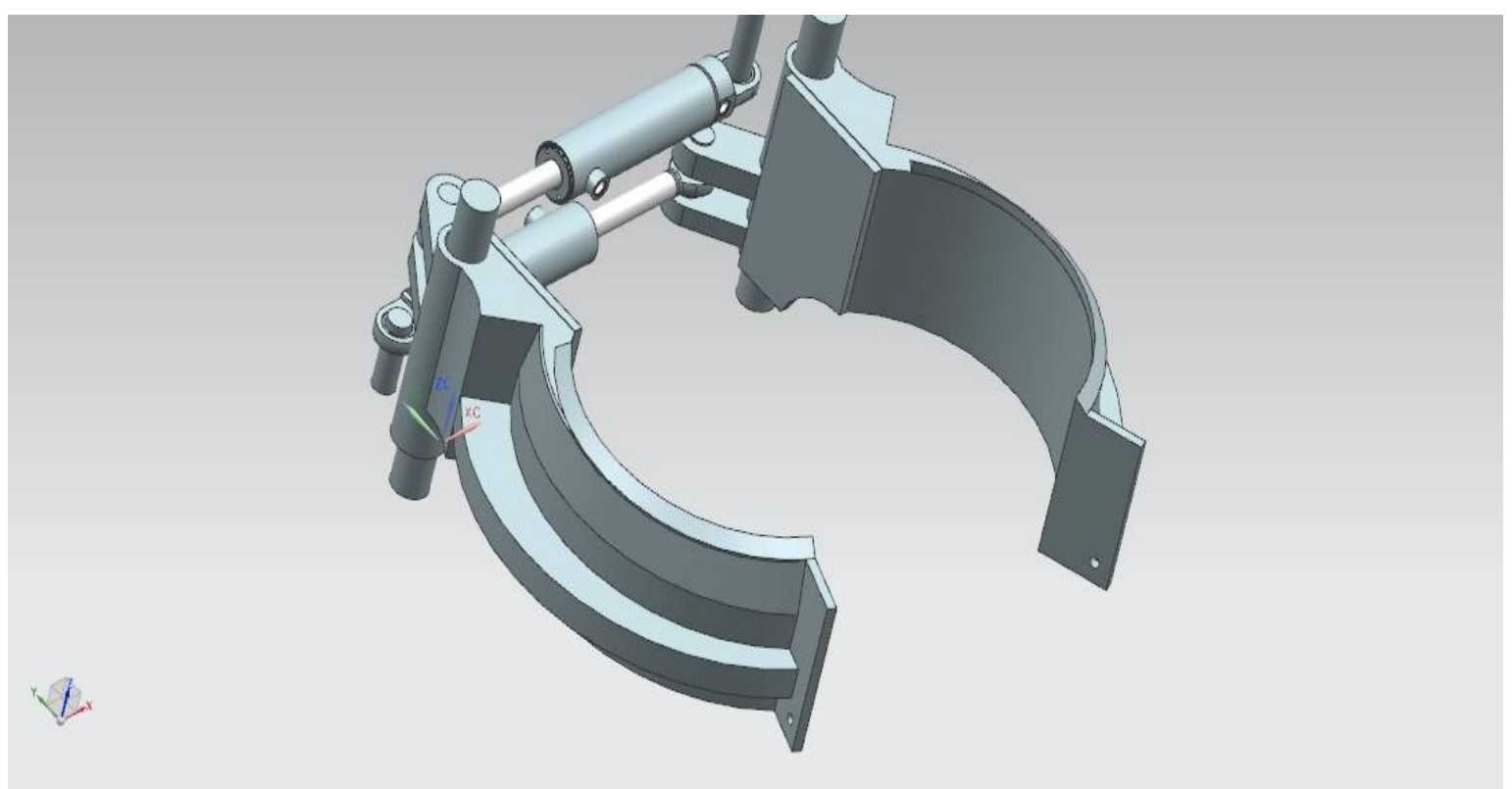

Fig. 2 - The subsystem for clamping the trunks 


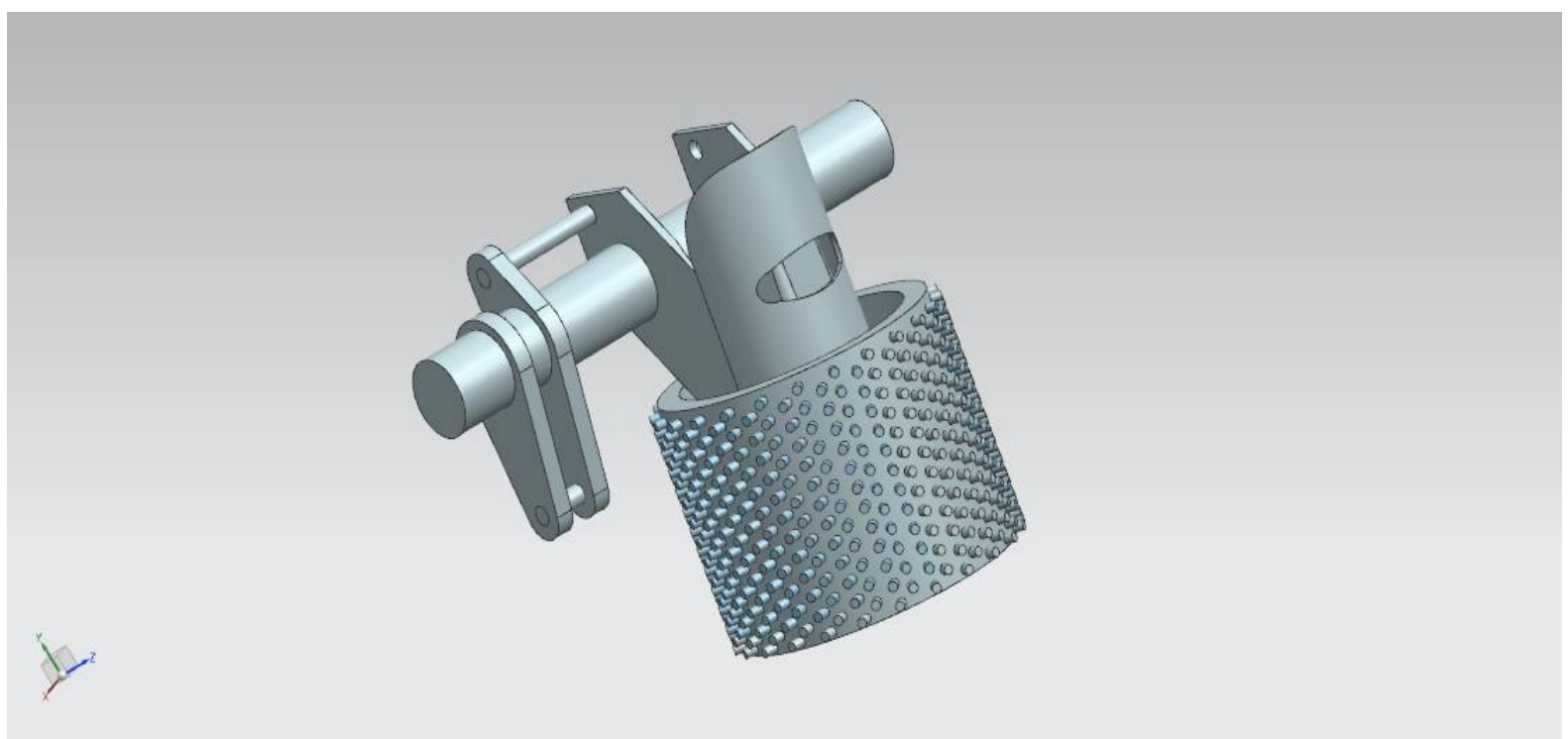

Fig. 3 - The subsystem of the rollers for advance

\subsection{THE SUBSYSTEM OF THE ROLLERS FOR ADVANCE}

The subsystem of the rollers (fig. 3) is composed of two special rollers with hinges, articulated by the housing with the help of the mounting brackets. To achieve the forward movement of the tree trunks, the rollers are driven by hydraulic motors that allow longitudinal advancement of the wood in both directions, with the help of 2 hydraulic cylinders the tree trunks are realized and this system ensures the longitudinal movement that contributes to the cleaning of branches and bark. This system also has a guard roll (support) mounted on the housing to avoid friction on the housing.

\subsection{THE SUBSYSTEM FOR CUTTING WITH CHAIN (CHAINSAW TYPE)}

The subsystem (fig. 4) for cutting with chain (chainsaw type) is composed of a hydraulic axial motor that drives the saw chain guided on the special support, a hydraulic cylinder that provides the pendulum movement required to cut the tree at the ground surface and its cutting to different lengths previously established.

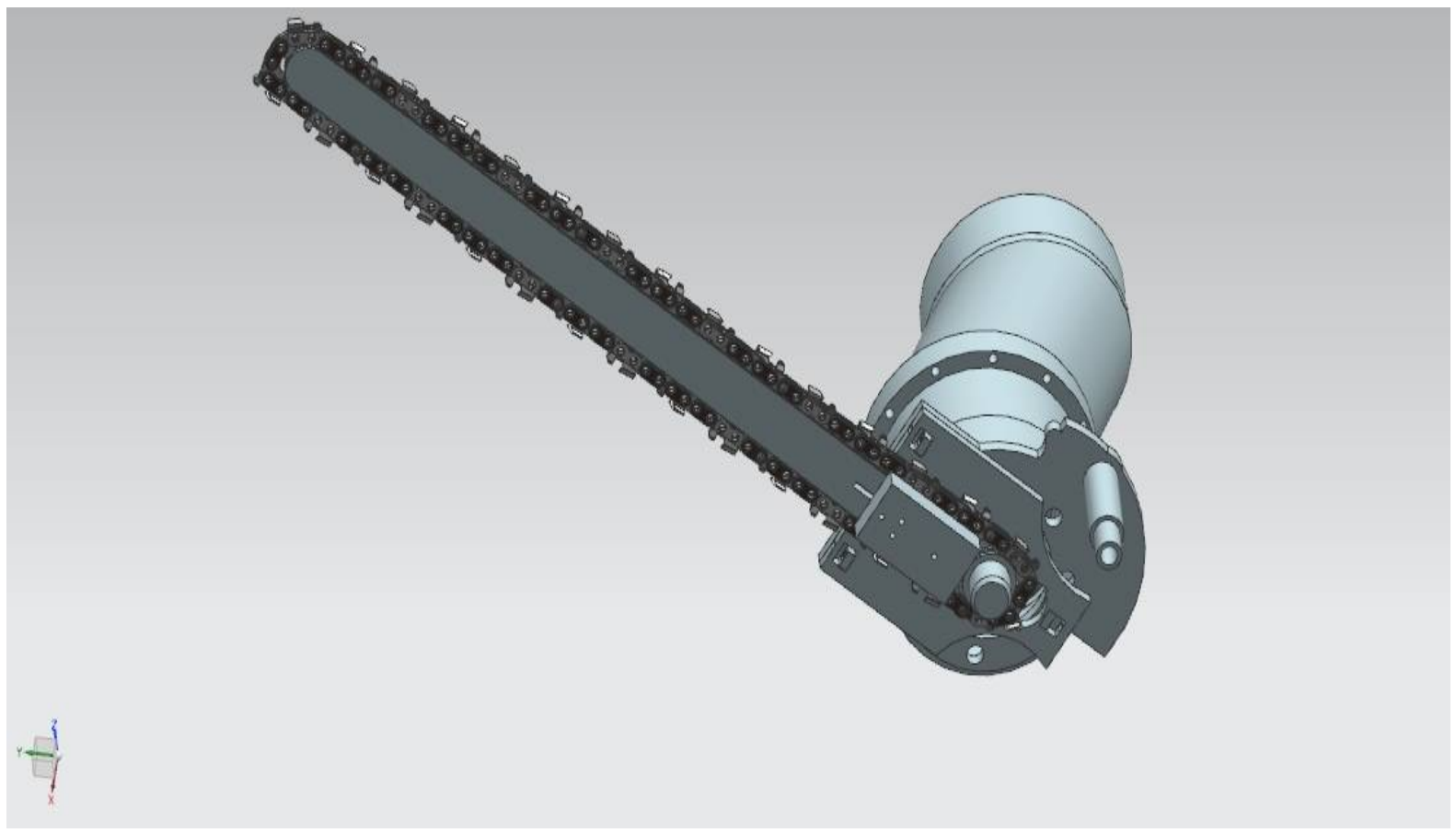

Fig. 4 - The subsystem for cutting with chain (chainsaw type) 


\section{CAE ANALYSIS OF THE REQUESTED PARTS \\ 3.1. 3D MODELING AND CAE ANALYSIS OF CLAMPS}

Figure 5 presents the 3D model of the clamps and figure 6 shows that the most strained area of the clamps is the middle curved part where the trunk support is realized during the longitudinal movement for cleaning branches and bark. The parts of the bearings for rotating clamps and their tips are less demanded due to the support of the trunk by the rollers for advance. The calculation of the resistance is done in the bending section of the jaws of the clamping system.

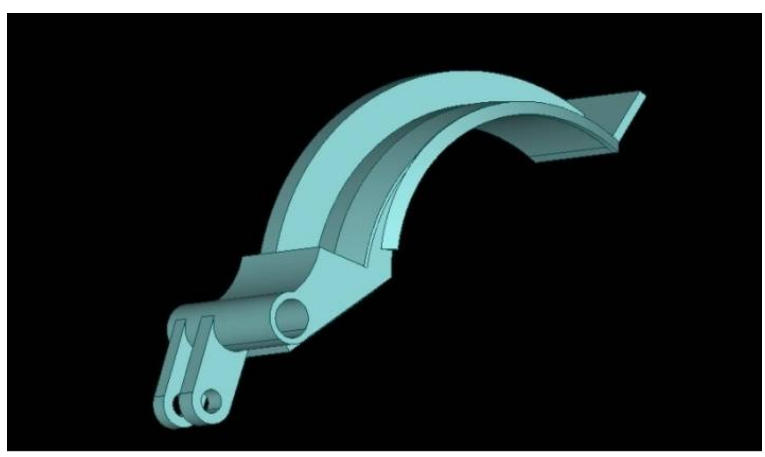

Fig. 5 - The 3D model of the claws

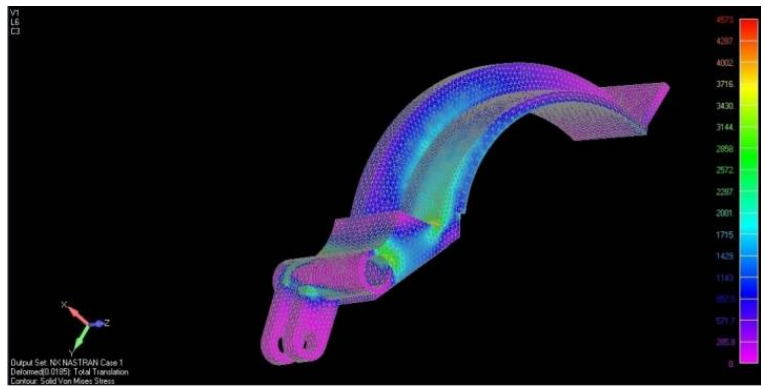

Fig. 6 - The CAE analysis of the claws 3D model

Figure 7 shows the 3D model rod of the hydraulic cylinder for clamping the claws. Figure 8 shows the strained areas of the hydraulic cylinder rod.

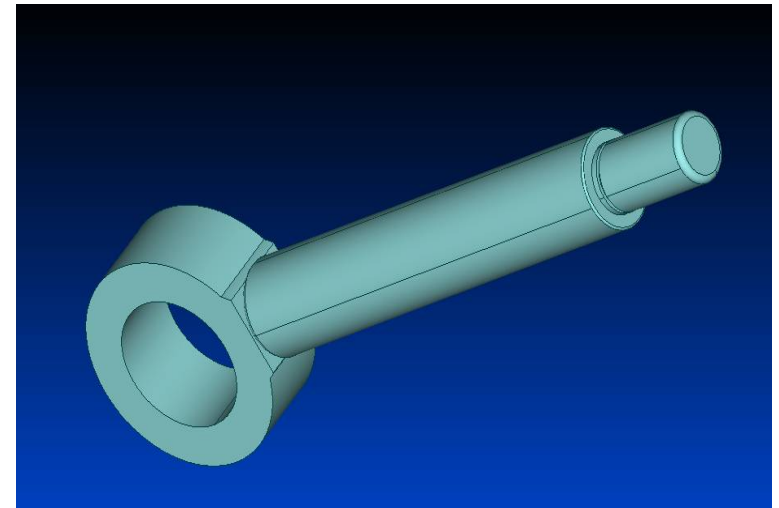

Fig. 7 - The3D model of the hydraulic cylinder rod

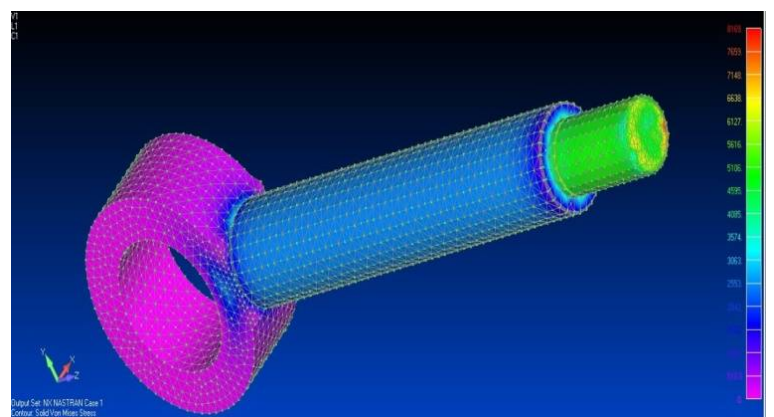

Fig. 8-CAE analysis of the 3D model of the hydraulic cylinder rod

\section{CONCLUSIONS}

The presented equipment responds to the technological requirements of productivity for the operation of harvesting the trees. The 3D modeling of this type of equipment allows additional checks on the correctness of the design as well as the static analysis of the most requested components. This reduces the production launch time and allows the mechanical processing on CNC machines. The $3 \mathrm{D}$ modeling and analysis of this type of multifunctional equipment allows the typing of this kind of product in order to launch in execution.

\section{REFERENCES}

[1] High-End solution CAD/CAM/CAE Siemens NX 8.0. 